Article

\title{
The Effect of Weighting Materials on Oil-Well Cement Properties While Drilling Deep Wells
}

\author{
Abdulmalek Ahmed $\odot$, Ahmed Abdulhamid Mahmoud $@$, Salaheldin Elkatatny *๑) and \\ Weiqing Chen $\mathbb{D}$ \\ College of Petroleum Engineering and Geosciences, King Fahd University of Petroleum \& Minerals, \\ 31261 Dhahran, Saudi Arabia; g201080240@kfupm.edu.sa (A.A.); eng.ahmedmahmoud06@gmail.com (A.A.M.); \\ jerromy@kfupm.edu.sa (W.C.) \\ * Correspondence: elkatatny@kfupm.edu.sa; Tel.: +966-594-663-692
}

Received: 21 October 2019; Accepted: 27 November 2019; Published: 29 November 2019

\begin{abstract}
In deep hydrocarbon development wells, cement slurry with high density is required to effectively balance the high-pressure formations. The increase in the slurry density could be achieved by adding different heavy materials. In this study, the effect of the weighting materials (barite, hematite, and ilmenite) on the properties of Saudi Class G cement matrix of vertical homogeneity, compressive strength, porosity, and permeability was evaluated. Three cement slurries were weighted with barite, hematite, and ilmenite, and cured at $294^{\circ} \mathrm{F}$ and 3000 psi for $24 \mathrm{~h}$. All slurries have the same concentration of the different additives except the weighting material. The amount of weighting material used in every slurry was determined based on the targeted density of $18 \mathrm{lbm} / \mathrm{gal}$. The results of this study revealed that the most vertically homogenous cement matrix was the ilmenite-weighted sample with a vertical variation of $17.6 \%$ compared to 20.2 and $24.8 \%$ for hematiteand barite-weighted cement, respectively. This is attributed to the small particle size of the ilmenite. The medical computerized tomography (CT) scan confirmed that the ilmenite-weighted sample is the most homogeneous, with a narrow range of density variation vertically along the sample. Hematite-weighted cement showed the highest compressive strength of $55.3 \mathrm{MPa}$, and the barite- and ilmenite-weighted cement compressive strengths are each 18.4 and $36.7 \%$ less than the compressive strength of the hematite-weighted cement, respectively. Barite-weighted cement has the lowest porosity and permeability of $6.1 \%$ and $18.9 \mathrm{mD}$, respectively. The maximum particle size of ilmenite used in this study is less than $42 \mu \mathrm{m}$ to ensure no abrasion effect on the drilling system, and it minimized the solids segregation while maintaining a compressive strength that is higher than the minimum acceptable strength, which is the recommended weighting material for Saudi Class G cement.
\end{abstract}

Keywords: oil-well cement; cement weighting material; barite; hematite; ilmenite; HPHT wells

\section{Introduction}

Primary oil-well cementing operations are conducted to achieve different functions, such as preventing fluid communication between the drilled formations and wellbore as well as flow between different formations, supporting the drilled formations and casing string, and protecting the casing from corrosive fluids attack [1-3].

In a primary cementing operation, a water-to-Class $\mathrm{G}$ cement $(\mathrm{w} / \mathrm{c})$ ratio of 0.44 is used as per the API standard [4], which makes a cement density of approximately $16.44 \mathrm{lbm} / \mathrm{gal}$ [5]. In deep oil wells, the use of cement with a higher density is required. Therefore, the weight of the cement can be increased by adding a weighting agent to the cement slurry. 
Barite $\left(\mathrm{BaSO}_{4}\right)$, ilmenite $\left(\mathrm{FeTiO}_{3}\right)$, and hematite $\left(\mathrm{Fe}_{2} \mathrm{O}_{3}\right)$ are the most commonly used weighting materials for cement [6-8]. In spite of its low cost, barite is rarely used as a weighting material for oil-well cement [9] because of its pollution potential, since it contains a considerable concentration of toxic heavy metals [10]. The typical particle size of barite is similar to Class G oil-well cement. The barite used as a weighting material for cement must have a specific gravity of about $4.2 \mathrm{~g} / \mathrm{cm}^{3}$ to meet the API specifications. Ilmenite has a lower concentration of heavy toxic metals compared to barite [10], and its particles are very coarse compared to barite, which means an increase in the abrasion effect on the drilling system [11]. However, the use of micronized ilmenite as a weighting material for the drilling fluids has been recently suggested, which resulted in an improvement in drilling fluids rheology [12-14] and a reduction in the abrasive effect on drilling system equipment [11]. Hematite, which is the most commonly used weighting material for cement, is finer than barite. Hematite is desired as a weighting material because of its high specific gravity, so a small amount of solids will be added to the cement slurry to achieve the required slurry density [15]. Hematite can also cause abrasion to the drilling equipment, and this problem could be prevented by using hematite with particles smaller than $45 \mu \mathrm{m}$ [16].

The use of any of the weighting materials could adversely affect the homogeneity of the cement by forming a cement matrix with varying density vertically along the cement body; this a direct result of solids segregation. Cement solids segregation could lead to alteration of cement properties such as porosity, permeability, and strength [17].

In addition to the segregation problem, in oil wells associated with high-pressure-high temperature (HPHT) conditions, alteration of the mechanical properties of the hydrated Portland cement is expected because of the adverse effect of the temperature on the cement hydrated products [18-21]. The conditions of elevated temperature are expected in deep wells, geothermal wells, and wells subjected to steam injection for enhanced oil recovery applications [22].

Portland cement experiences major chemical and microstructural transformations under high-temperature conditions $\left(>110^{\circ} \mathrm{C}\right)$. Such a phenomenon is known as strength retrogression, which increases as long as the temperature increases beyond $110{ }^{\circ} \mathrm{C}[23,24]$. During the strength retrogression transformation, calcium-rich products are formed in the cement matrix, which will increase the matrix porosity and permeability and deteriorate its mechanical properties.

Although the addition of weighting materials to cement considerably alters its properties, only a few previous studies have evaluated the change in cement slurry characteristics as a function of the weighting material $[9,15]$. The high specific gravity of the weighting materials leads to problems such as solid particles segregation, especially when the cement slurry contains components of large particle size [25], and this problem causes the hydrated cement sheath to have considerably varying properties vertically along the solidified cement body, especially the cement density, porosity, and permeability.

The goal of this study is to evaluate the effect of using different weighting materials on the cement matrix properties such as vertical homogeneity, compressive strength, porosity, and permeability, for cement slurries prepared with a density of $18 \mathrm{lbm} / \mathrm{gal}$ and cured at HPHT conditions of $294^{\circ} \mathrm{F}$ and 3000 psi.

\section{Materials and Methods}

\subsection{Materials}

Three cement slurries with composition summarized in Table 1 were prepared. The slurries were prepared with the same concentration of Saudi Class G cement, silica flour, fluid loss additive, dispersant, retarder, defoamer, and water. All cement slurries were prepared to have a similar density of $18 \mathrm{lbm} / \mathrm{gal}$, and based on this the concentration of the weighting additives (i.e. barite, ilmenite, and hematite) was varied to achieve a consistent density $(18 \mathrm{lbm} / \mathrm{gal})$. The cement formulations summarized in Table 1 were provided by a service company. These formulations are commonly used for cementing deep oil wells in Saudi Arabia. 
Table 1. The composition of the cement slurries prepared in this study; additives are in the unit of "by weight of cement (BWOC)."

\begin{tabular}{ccccc}
\hline \multirow{2}{*}{} & Component & \multicolumn{3}{c}{ BWOC (\%) } \\
\cline { 3 - 5 } \cline { 3 - 4 } & & Barite-Weighted & Hematite- Weighted & Ilmenite- Weighted \\
\hline & Saudi Class G Cement & 100 & 100 & 100 \\
& Silica Flour & 35 & 35 & 35 \\
& Fluid Loss Additive & 0.5 & 0.5 & 0.5 \\
& Dispersant & 0.25 & 0.25 & 0.25 \\
& Retarder & 1.5 & 1.5 & 1.5 \\
Heavy & Defoamer & $4.7 \times 10^{-7}$ & $4.7 \times 10^{-7}$ & $4.7 \times 10^{-7}$ \\
Weighting & Water & 44 & 44 & 0 \\
Materials & Barite & 37.6 & 0 & 0 \\
\hline & Hematite & 0 & 32.9 & 36.3 \\
\hline
\end{tabular}

Saudi Class G cement with the composition summarized in Table 2 as characterized by the X-ray fluorescence (XRF) and all other additives was provided by a service company. The water used was deionized water.

Table 2. The elemental composition of Class G cement, as characterized by X-ray fluorescence (XRF).

\begin{tabular}{cc}
\hline Component & Concentration (wt \%) \\
\hline Silica & 21.6 \\
Alumina & 3.30 \\
Iron Oxide & 5.99 \\
Calcium Oxide & 64.2 \\
Magnesium Oxide & 1.10 \\
Sulphur Trioxide & 2.20 \\
Loss on Ignition & 0.90 \\
Insoluble Residue & 0.30 \\
Equivalent Alkali & 0.41 \\
\hline
\end{tabular}

Figure 1 compares the particle size distribution for Saudi Class G cement, barite, hematite, and ilmenite. As shown in Figure 1, barite has a particle size distribution similar to Saudi Class G cement, where $\mathrm{D}_{50}$ for Saudi Class $\mathrm{G}$ cement is $12.15 \mu \mathrm{m}$, and for barite it is $11.67 \mu \mathrm{m}$. Hematite has a particle size finer than barite with $\mathrm{D}_{50}$ of $9.41 \mu \mathrm{m}$. Ilmenite was the finest weighting materials used in this study, with a $\mathrm{D}_{50}$ of $8.03 \mu \mathrm{m}$. The ilmenite used in this study has a particle size of less than $42 \mu \mathrm{m}$. Blomberg et al. [11] reported based on experimental work that the use of ilmenite with less than $3 \%$ of particles of $45 \mu \mathrm{m}$ or more prevented drilling system abrasion, which indicates that the ilmenite used in this study will not cause any abrasion problems to the drilling system.

Table 3 compares the specific gravity of Saudi Class G cement and the weighting materials used in this study.

Table 3. The specific gravity of Saudi Class G cement and the weighting materials used in this study.

\begin{tabular}{cc}
\hline Material & Specific Gravity \\
\hline Saudi Class G & 3.15 \\
cement & 4.20 \\
Barite & 5.10 \\
Ilmenite & 4.95 \\
Hematite & \\
\hline
\end{tabular}




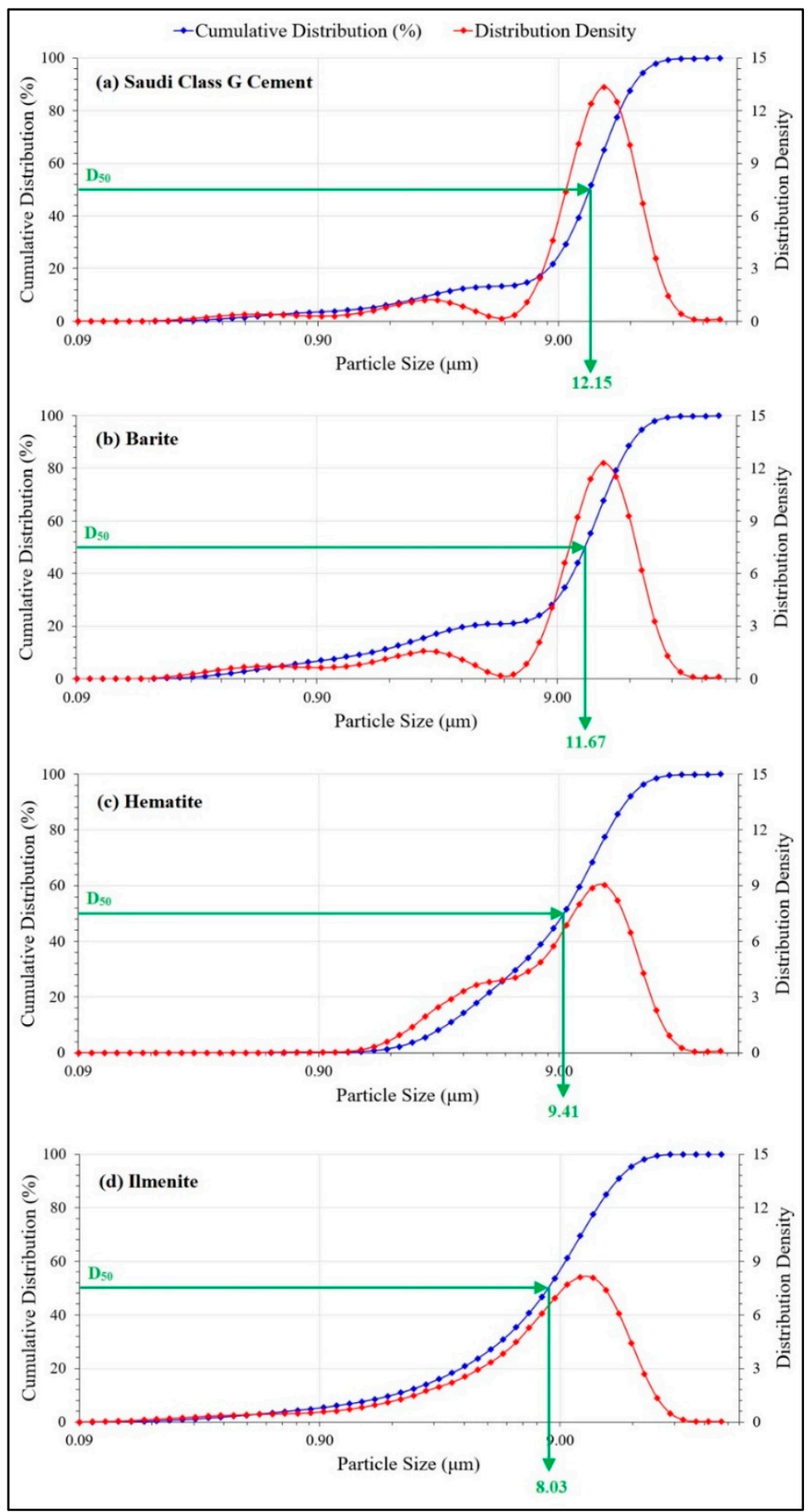

Figure 1. Particle size distribution for (a) Saudi Class G cement, (b) barite, (c) hematite, and (d) ilmenite. The green arrows in this figure indicate the $\mathrm{D}_{50}$.

\subsection{Samples Preparation}

The cement slurries were prepared according to the API standard [4]. After preparation, the slurries were poured into metallic molds of two different dimensions based on the targeted test, as will be detailed in the following sections. The first kind of molds is cubical with 2" edges, and the second one is cylindrical with a $1.5^{\prime \prime}$ diameter and a $4^{\prime \prime}$ length. The samples were then cured at $294^{\circ} \mathrm{F}$ and 3000 psi using an HPHT curing chamber. The curing conditions used in this study are the same conditions provided to us by the cement formulations provider (service company). After $24 \mathrm{~h}$ of curing, the cement samples were removed from the curing chamber and demolded based on the metallic molds to be evaluated for the change in their different properties. 


\subsection{Density Variation}

Density variation was studied using three cylindrical samples with a $1.5^{\prime \prime}$ diameter and a 4 " length, representing the three kinds of specimens considered in this study. The density change was evaluated through the medical computerized tomography (CT) scan imaging technique and direct density measurement. The three cylindrical cement samples of $1.5^{\prime \prime}$ diameter and 4 " length were first CT-scanned from the top to the bottom to identify the density at every section along the samples at a spacing of about $1.2 \mathrm{~mm}$ between the slices and a voxel resolution of $1 \mathrm{~mm}$, and each image had dimensions of $512 \times 512$ pixels. Small cement cylinders were then cut (based on the cylindrical samples of $1.5^{\prime \prime}$ diameter and 4 " length) at three sections representing the top, middle, and bottom sections of the cement samples; the three small cement cylinders with $1.5^{\prime \prime}$ diameter and $0.5^{\prime \prime}$ length were cut exactly at the top, center, and bottom of the large cement cylinders to fairly compare the density variation in the three locations along the large cylindrical cement samples. The density was determined as a function of the volume and weight of the small cement cylinders.

\subsection{Compressive Strength Measurement}

For compressive strength evaluation, three cubical samples of 2" edges representing each cement specimen under evaluation were prepared and tested following the API and ASTM standards [26,27]. To evaluate the compressive strength, the samples were continually subjected to compression load at a rate of $1.5 \mathrm{KN} / \mathrm{s}$ until the samples failed under compression. The maximum compression load that the sample could withstand represents its compressive strength. The compressive strength of every specimen was then calculated as an average compressive strength of three samples. The crushing machine used for compressive strength measurement is shown in Figure 2a.

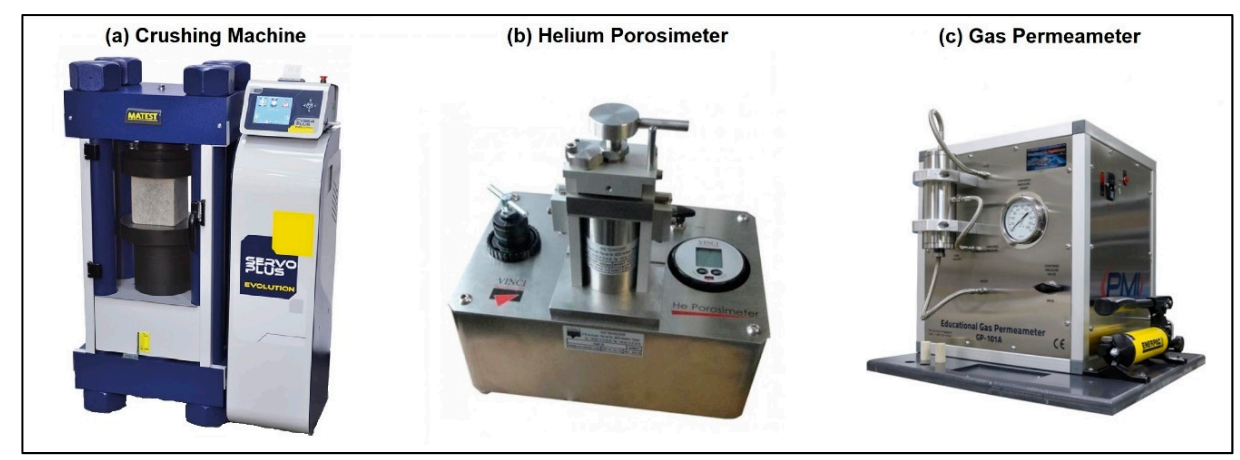

Figure 2. (a) The crushing machine used to determine the maximum load that the samples could withstand under compression and tension, (b) the helium porosimeter used for porosity evaluation, and (c) the gas permeameter used for permeability measurement; nitrogen was used as measuring fluid for permeability evaluation.

\subsection{Tensile Strength Measurement}

Cement cylinders of $1.5^{\prime \prime}$ in diameter and $0.9^{\prime \prime}$ in length were used to evaluate the cement tensile strength using indirect measurement (Brazilian tensile strength) by averaging three replicas. [28,29].

The tensile strength was determined indirectly as a function of the maximum load that the sample could withstand before failing and the sample's dimensions using Equation (1).

$$
\sigma_{t}=\frac{2 \mathrm{P}}{\pi d l}
$$

where $\sigma_{t}$ is the Brazilian tensile strength in $(\mathrm{MPa}), P$ denotes the maximum load the sample could withstand before failure in $(\mathrm{N})$, and $d$ and $l$ denote the diameter and length of the cement sample, respectively, both in ( $\mathrm{mm})$. The crushing machine used for tensile strength measurement is shown in Figure 2a. 


\subsection{Porosity and Permeability Measurement}

Cylindrical samples of $1.5^{\prime \prime}$ in diameter and $4 "$ in length were used to measure the porosity and permeability. The porosity was measured according to Boyle's law [30] and using the helium porosimeter, which is the same procedure followed by Mahmoud and Elkatatny [31] and Mahmoud et al. [32]. The permeability was measured according to the procedures explained by Sanjuán and Muñoz-Martialay [33] and with the use of the Hagen-Poiseuille law, which is widely used to evaluate the permeability of the porous media using compressible fluid that undergoes laminar flow at steady-state conditions. The helium porosimeter and gas permeameter are shown in Figure 2b,c, respectively; nitrogen was used as the measuring fluid for permeability quantification.

\section{Results and Discussion}

\subsection{Density Variation}

Figure 3 compares the density variation along the cement samples considered in this study. This figure compares the density values at the top, middle, and bottom of all cement samples and the percentage density variation between the top and bottom of each sample. As shown in Figure 3 , the density variation along the barite-weighted cement sample was the highest, with a density variation between the sample's top to bottom of $24.8 \%$, followed by the hematite-weighted sample with a $20.2 \%$ density variation. The most homogeneous sample was the ilmenite-weighted sample, which had a vertical density variation of $17.6 \%$ from top to bottom. This result could be explained as a direct relation to the particle size distribution for every weighting material explained earlier and compared in Figure 1, and it confirms that the use of weighting material that has large particles could result in vertical heterogeneity. Several previous studies have confirmed that reducing the particle size of the weighing material such as barite and ilmenite used with drilling fluid can prevent solids settlement [34] and improve the properties of the drilling fluids $[14,35,36]$.

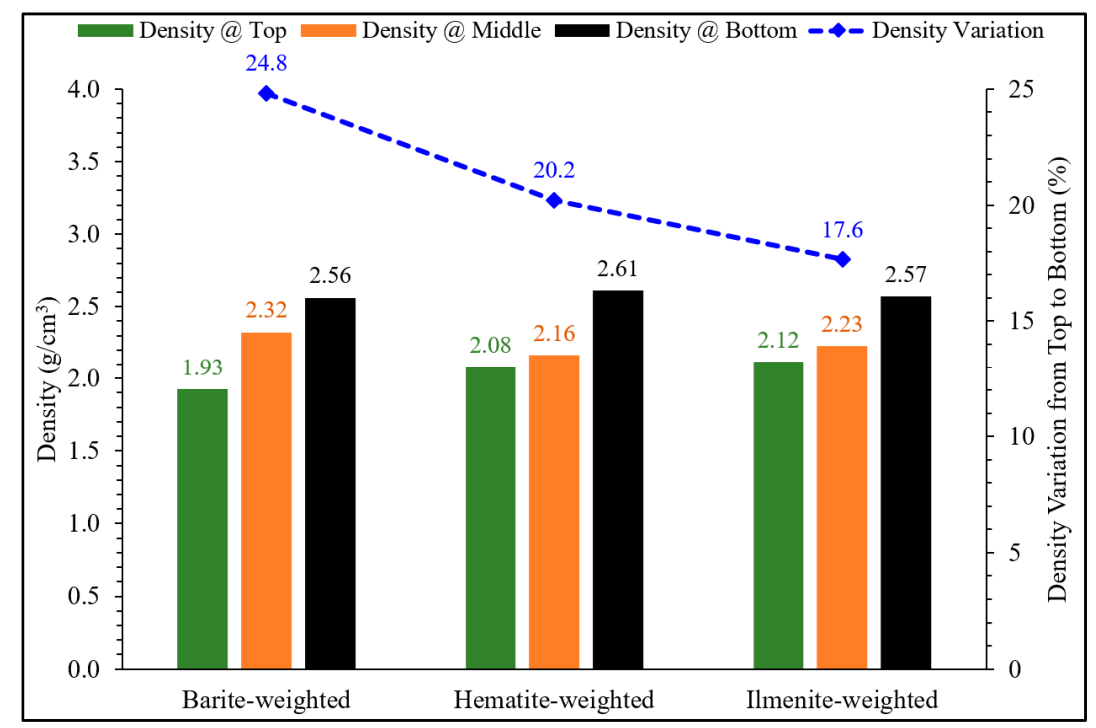

Figure 3. Densities of the cement slices at the top, middle, and bottom of the cement cylinders cured at $294^{\circ} \mathrm{F}$ and 3000 psi for $24 \mathrm{~h}$.

Figure 4 shows the density variation along the cement cylinders as characterized by the CT scan. The slices in Figure 4 represent different sections along the cement cylinders. The different colors of the circles in Figure 4 indicate the density difference. Blue refers to lower density, red represents medium density, and orange is for higher density, while yellow represents the highest density sections. As shown in Figure 4a, the density of the cement sample significantly varied along the barite-weighted sample, where Slices 1-35 (almost the top half of the sample) are blue. The density of the bottom 
half of this sample varied considerably, where Slices 36-40 are blue/red, Slices 41-46 are red, Slices 47-56 are red/orange, Slices 57-64 are orange, and Slices 65-80 (bottom of the sample) are yellow. This result indicates that, for the barite-weighted sample, the top half of the sample had a lower density compared to the bottom of the sample, confirming that the density sharply changed axially along the barite-weighted sample. As indicated in Figure 4b, the hematite-weighted sample also showed a considerable and sharp variation between its top and bottom sections.
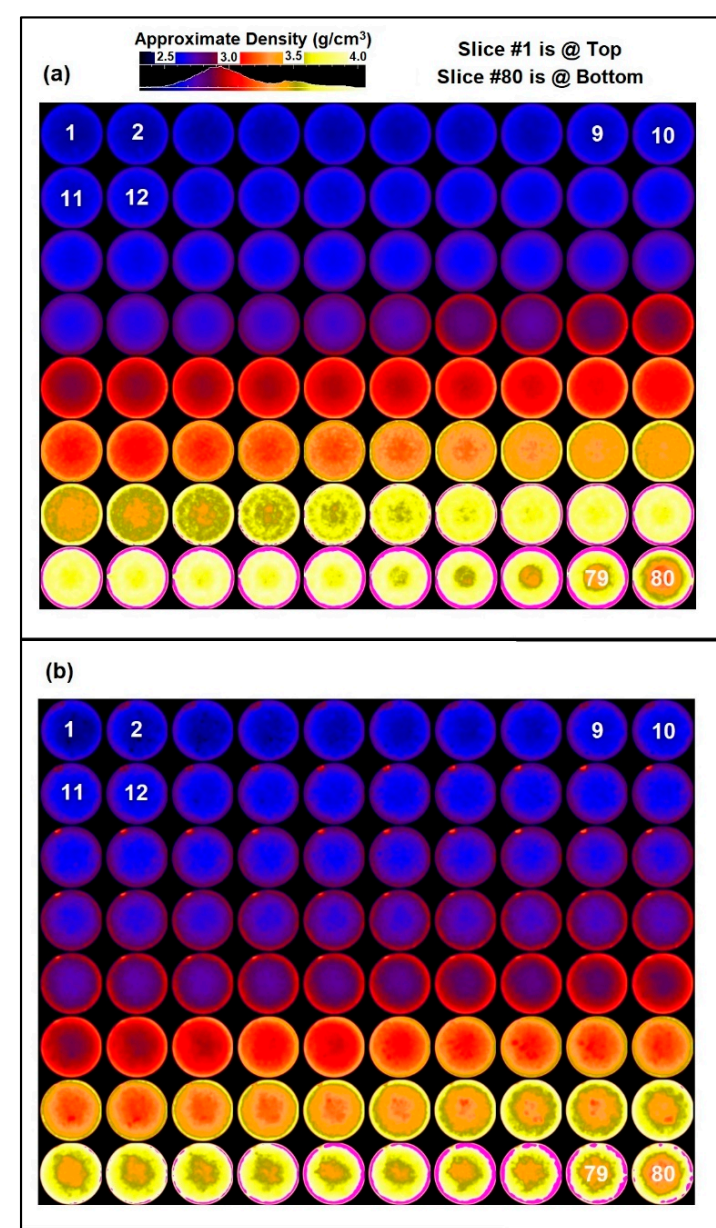

(c)

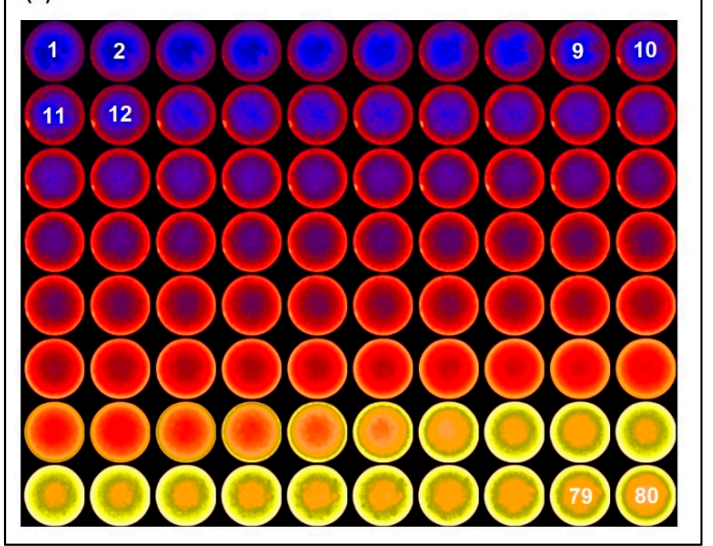

Figure 4. CT scan images representing the density distribution throughout the cement cylinders from the top section (Slice 1) to the bottom section (Slice 80) for (a) barite-weighted, (b) hematite-weighted, and (c) ilmenite-weighted cement samples. 
The ilmenite-weighted sample (Figure 4c) had a much more moderate density variation, Slices 1-30 are blue with a small amount of red, Slices 31-40 are blue/red, Slices 41-50 are red with light blue, Slices 51-65 are red with a small amount of orange, and Slices 66-80 are orange. This result confirms the small and gradual density variation axially along the hematite-weighted cement sample.

The previous results indicated that the use of ilmenite with a maximum particle size of $42 \mu \mathrm{m}$ minimized the problem of solids segregation. The low solids segregation for ilmenite-weighed cement samples could also be further reduced by adding a dispersion agent to the cement slurry [17]. We must note that the density values as measured by the CT technique are approximate as indicated in the density scale in Figure 3. These values are less accurate compared with the density values reported in Figure 3, which are calculated directly as a function of the sample's weight and dimensions.

\subsection{Compressive Strength}

The compressive strength of the three types of cement samples evaluated in this study is compared in Figure 5. The hematite-weighted sample had the highest compressive strength of $55.3 \mathrm{MPa}$, followed by the barite-weighted cement which had a compressive strength of $45.1 \mathrm{MPa}(18.4 \%$ less than the compressive strength of the hematite-weighted sample), while the ilmenite-weighted cement sample had the lowest compressive strength of $36.1 \mathrm{MPa}$, which is $36.7 \%$ less than the compressive strength of the hematite-weighted sample. Although the ilmenite-weighted cement had the lowest compressive strength among the other samples, the compressive strength of the ilmenite-weighted cement after $24 \mathrm{~h}$ of curing (36.1 MPa) was greater than $1000 \mathrm{psi}(6.89 \mathrm{MPa})$, which is the minimum acceptable compressive strength for cement after 7 days of curing [37].

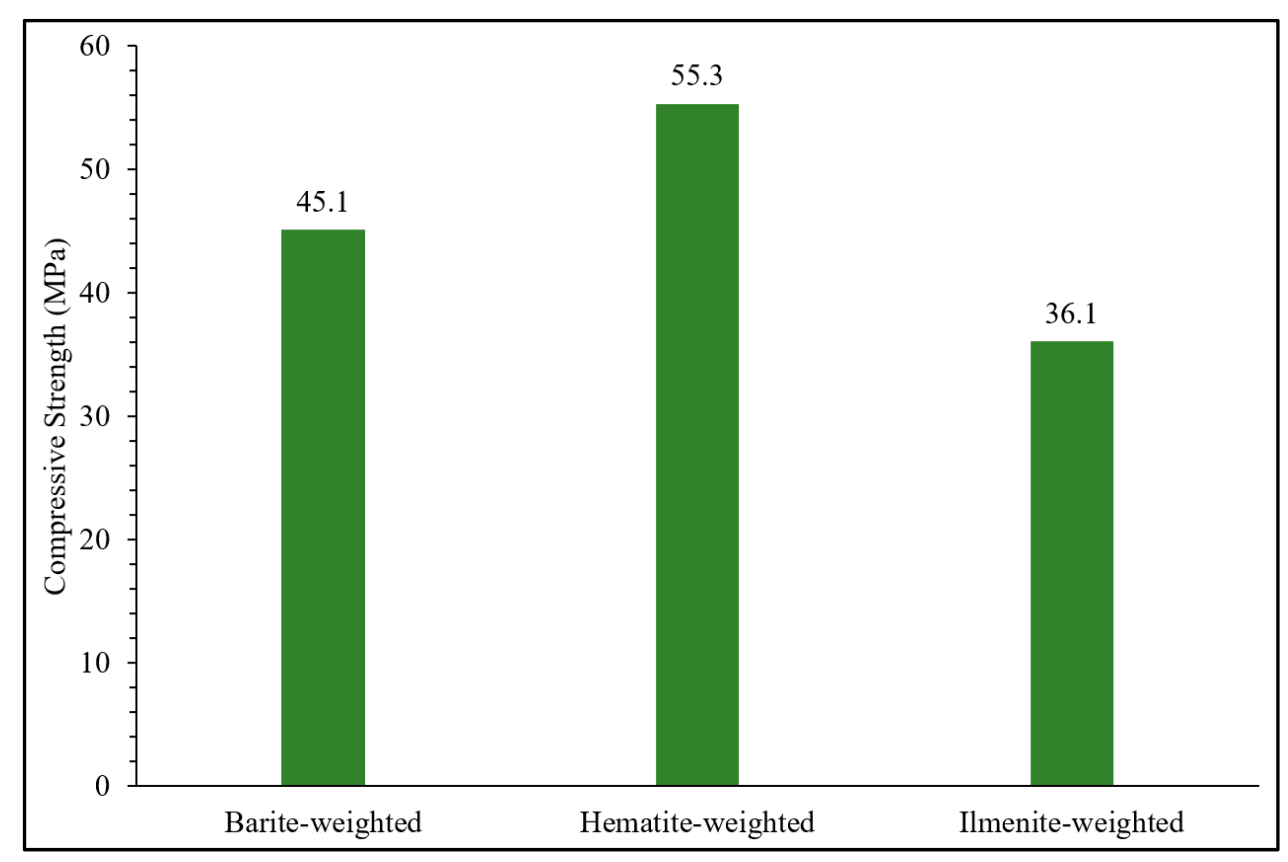

Figure 5. Compressive strength of the cement samples prepared and cured at $294^{\circ} \mathrm{F}$ and 3000 psi for $24 \mathrm{~h}$.

\subsection{Porosity and Permeability}

Figure 6 compares the porosity and permeability changes due to the inclusion of the weighting materials into the cement samples. As shown in Figure 6, the barite-weighted cement sample had the lowest porosity and permeability values. The ilmenite-weighted sample's porosity and permeability ranked between the barite-weighted sample and the hematite-weighted sample. The porosity and permeability of the ilmenite-weighted sample were 47.09 and $772.13 \%$ greater than the porosity and permeability of the barite-weighted sample, respectively. The hematite-weighted sample had 
the highest porosity and permeability, which were $52.38 \%$ and $937.7 \%$ greater than those for the barite-weighted sample, respectively. Although the particle size of the barite was the highest among other weighting materials, the concentration of the barite used was also the highest (Table 1) and could explain why the barite-weighted cement had less porosity and permeability.

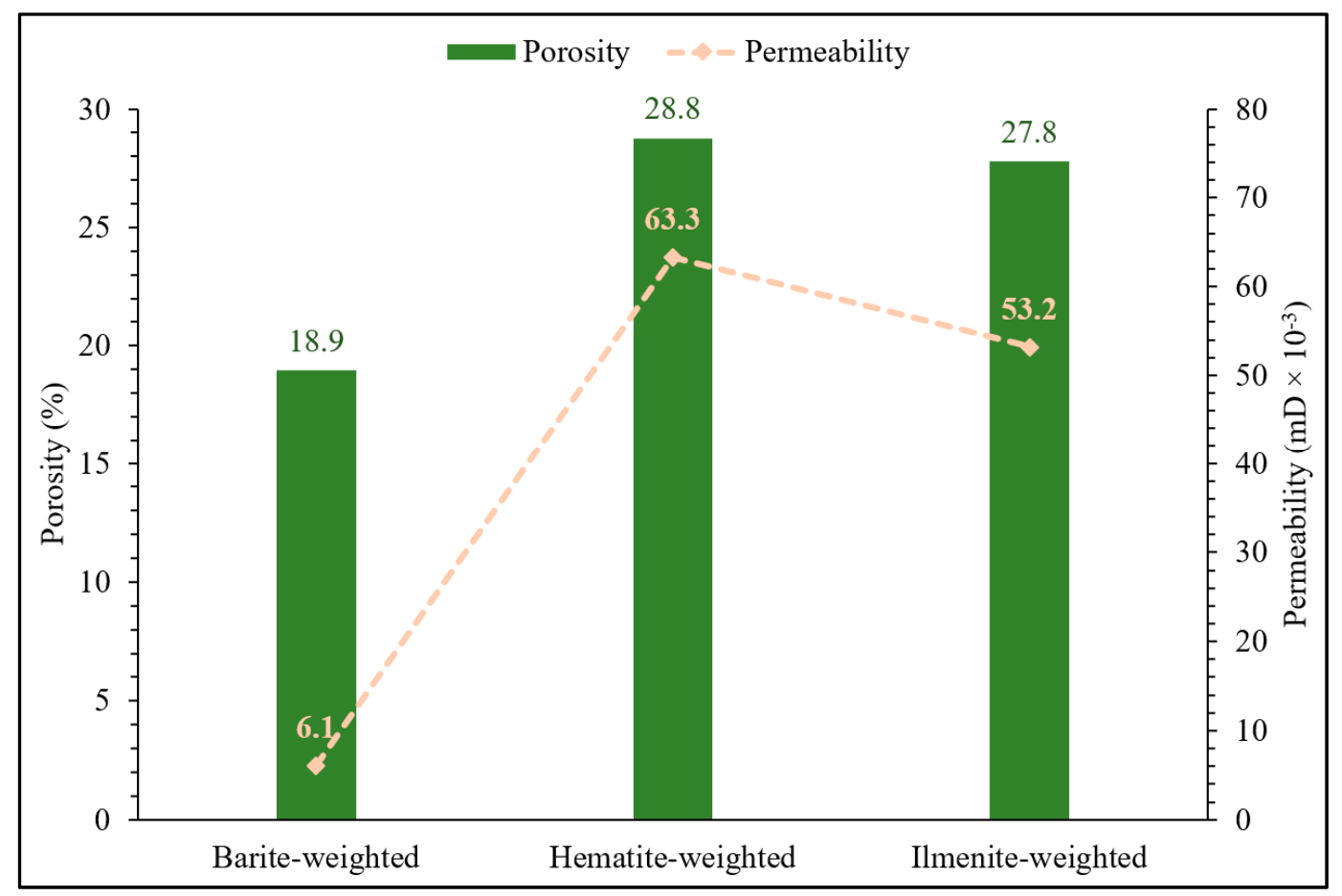

Figure 6. Porosity and permeability of the cement samples prepared and cured at $294{ }^{\circ} \mathrm{F}$ and $3000 \mathrm{psi}$ for $24 \mathrm{~h}$.

\section{Conclusions}

In this study, the effect of three weighting materials, namely barite, hematite, and ilmenite, on Saudi Class G cement matrix properties in terms of vertical homogeneity, compressive strength, porosity, and permeability was studied. The cement samples were prepared with a density of $18 \mathrm{lbm} / \mathrm{gal}$ and cured for $24 \mathrm{~h}$ at $294^{\circ} \mathrm{F}$ and $3000 \mathrm{psi}$. The results of this study showed the following:

- Ilmenite was the best in producing a vertical homogeneous cement sheath with a variation of $17.6 \%$ compared to hematite-weighted $(20.2 \%)$ and barite-weighted $(24.8 \%)$ samples, respectively. This may be attributed to the small particle size of the ilmenite $(<42 \mu \mathrm{m})$.

- The medical computerized tomography (CT) scan confirmed that the ilmenite-weighted cement is the most homogeneous sample with a narrow range of density variation axially along the sample.

- Hematite-weighted cement has the highest compressive strength of $55.3 \mathrm{MPa}$, while the compressive strengths of barite-weighted and ilmenite-weighted cement are $18.4 \%$ and $36.7 \%$ less than the hematite-weighted, respectively.

- Barite-weighted cement has the lowest porosity and permeability of $6.1 \%$ and $18.9 \mathrm{mD}$.

- Overall, ilmenite weighting material used in this work was the best because it has a maximum particle size of less than $42 \mu \mathrm{m}$; this small size of ilmenite helps in preventing an abrasion effect on the drilling system, and it minimized the solids segregation while maintaining a compressive strength that was higher than the minimum acceptable strength. 


\section{Recommendation}

For future work, based on the results of this study, the following points are recommended for the industry:

- Segregation problems associated with cement slurries weighted with barite, hematite, or ilmenite could be decreased by reducing the particle size of the weighting material.

- Reducing the particle size of the weighting materials is also necessary to prevent the problem of solid abrasion.

- The problem of solids segregation could also be further reduced by using a dispersion agent.

- For future work, we recommend the use of micronized barite and micronized hematite (with less than $3 \%$ of the particles of $45 \mu \mathrm{m}$ and higher) as weighting material to solve the problem of solids segregation.

Author Contributions: Conceptualization, S.E.; methodology, S.E. and A.A.; laboratory work, A.A., formal analysis, A.A.M. and W.C.; data preparation, A.A.M. and A.A.; writing - original draft preparation, A.A.M.; writing - review and editing, A.A.M., W.C., and S.E.; visualization, A.A.M., W.C., and S.E.; supervision, S.E.

Funding: This research received no external funding.

Conflicts of Interest: The authors declare no conflict of interest.

\section{References}

1. Adams, N.J. Cementing. In Drilling Engineering: A Complete Well Planning Approach; Pennwell Publishing Company: Tulsa, OK, USA, 1985; p. 279. ISBN 0878142657.

2. Mitchell, R.F.; Miska, S.Z. Fundamentals of Drilling Engineering; Society of Petroleum Engineers, Inc.: Richardson, TX, USA, 2011; Chapter 4; ISBN 978-1-55563-207-6.

3. Rabia, H. Well Engineering and Construction; Entrac Petroleum: London, UK, 2001; Chapter 6; ISBN 0954108701.

4. API. Recommended Practice 10B-2: Recommended Practice for Testing Well Cements, 2nd ed.; American Petroleum Institute: Washington, DC, USA, 2013.

5. Mahmoud, A.A.; Elkatatny, S.; Ahmed, S.A.; Gajbhiye, R. Influence of Nanoclay Content on Cement Matrix for Oil Wells Subjected to Cyclic Steam Injection. Materials 2019, 12, 1452. [CrossRef] [PubMed]

6. Hossain, E.; Al-Majed, A.A. Cementing. In Fundamentals of Sustainable Drilling Engineering; Scrivener Publishing LLC: Beverly, MA, USA, 2015; p. 531. ISBN 978-0-470-87817-0.

7. Moore, P.L. Primary Cementing. In Drilling Practices Manual, 2nd ed.; Pennwell Publishing Company: Tulsa, OK, USA, 1986; ISBN 0-87814-292-4.

8. Nelson, E.B.; Baret, J.F.; Michaux, M. Cement Additives and Mechanism of Action, in Well Cementing; Elsevier: Amsterdam, The Netherlands, 1990; pp. 3-1-3-37. [CrossRef]

9. Atashnezhad, A.; Coryell, T.; Hareland, G. Barite Nanoparticles Reduce the Cement Fluid Loss. In Proceedings of the SPE Oklahoma City Oil and Gas Symposium, Oklahoma City, OK, USA, 27-31 March 2017. SPE-185114-MS. [CrossRef]

10. Rae, P.; Di Lullo, G.; bte Ahmad, A. Towards Environmentally-Friendly Additives for Well Completion and Stimulation Operations. In Proceedings of the SPE Asia Pacific Oil and Gas Conference and Exhibition, Jakarta, Indonesia, 17-19 April 2001. SPE-68651-MS. [CrossRef]

11. Blomberg, N.E.; Melberg, B.; Boe, A.; Jacobsen, E.; Aarrestad, S. Evaluation of Ilmenite as Weight Material in Drilling Fluids. J. Pet. Technol. 1984, 36, 969-974. [CrossRef]

12. Al-Bagoury, M. Micronized ilmenite-A non-damaging and nonsagging new weight material for drilling fluids. In Proceedings of the SPE Bergen, Bergen, Norway, 2 April 2014. SPE-169182-MS. [CrossRef]

13. Steele, C.; Al-Bagoury, M. Micronised ilmenite-A new intermediate weight material for drilling fluids. In Proceedings of the AADE Fluids Technical Conference and Exhibition held at the Hilton Houston North Hotel, Houston, TX, USA, 10-11 April 2012. AADE-12-FTCE-12.

14. Xiao, J.; Nasr-El-Din, H.A.; Al-Bagoury, M. Evaluation of Ilmenite as a Weighting Material in Oil-based Drilling Fluids for HPHT Applications. In Proceedings of the SPE European Formation Damage Conference \& Exhibition, Noordwijk, The Netherlands, 5-7 June 2013. SPE-165184-MS. [CrossRef] 
15. Saasen, A.; Log, P.A. The effect of ilmenite plant dusts on rheological properties of class $\mathrm{G}$ oil well cement slurries. Cem. Concr. Res. 1996, 26, 707-715. [CrossRef]

16. Bizanti, M.S.; Moonesan, A.; Caruthers, R.M. Reduction Feasibility of Itabirite Mud Abrasion. In Proceedings of the SPE Formation Damage Control Symposium, Bakersfield, California, 8-9 February 1988. SPE-17163-MS. [CrossRef]

17. Elkatatny, S. Development of a Homogenous Cement Slurry Using Synthetic Modified Phyllosilicate while Cementing HPHT Wells. Sustainability 2019, 11, 1923. [CrossRef]

18. Caritey, J.P.; Brady, J. Performance of Thermal Cements with Different Weighting Materials. In Proceedings of the SPE/IADC Drilling Conference, Amsterdam, The Netherlands, 5-7 March 2013. SPE-163544-MS. [CrossRef]

19. Costa, B.L.S.; Souza, G.G.; Freitas, J.C.O.; Araujo, R.G.S.; Santos, P.H.S. Silica content influence on cement compressive strength in wells subjected to steam injection. J. Pet. Sci. Eng. 2017, 158, 626-633. [CrossRef]

20. Karim, M.R.; Chowdhury, F.I.; Zabed, H.; Saidurd, M.R. Effect of elevated temperatures on compressive strength and microstructure of cement paste containing palm oil clinker powder. Constr. Build. Mater. 2018, 183, 376-383. [CrossRef]

21. Szelag, M. The Influence of Metakaolinite on the Development of Thermal Cracks in a Cement Matrix. Materials 2018, 11, 520. [CrossRef] [PubMed]

22. Alvarez, J.; Han, S. Current overview of cyclic steam injection process. J. Pet. Sci. Res. 2013, 2, 116-127. Available online: https://pdfs.semanticscholar.org/da65/1f5b040fa45b6ad31c8435eca1584125a254. pdf (accessed on 1 October 2019).

23. Taylor, H.F.W. Cement Chemistry, 1st ed.; Thomas Telford Publishing: London, UK, 1990; ISBN 0727725920.

24. Nelson, E.B.; Guillot, D. Well Cementing, 2nd ed.; Schlumberger: Sugar Land, TX, USA, 2006; ISBN 0978853008.

25. Malyshev, A.; Doronina, T.; Popov, M.; Ryabchikov, A.; Shulga, V. Optimized Particles Size Distribution Lightweight Cement at Low Temperatures: Case Study from Eastern Siberia, Russia (Russian). In Proceedings of the SPE Arctic and Extreme Environments Technical Conference and Exhibition, Moscow, Russia, 15-17 October 2013. SPE-166849-MS. [CrossRef]

26. API. API Specification 10A: Cements and Materials for Well Cementing, 25th ed.; American Petroleum Institute: Washington, DC, USA, 2019.

27. ASTM. ASTM C109/C109M. Standard Test Method for Compressive Strength of Hydraulic Cement Mortars (Using 2-In. or [50-Mm] Cube Specimens); ASTM International: West Conshohocken, PA, USA, 2016.

28. Mahmoud, A.A.; Elkatatny, S. Mitigating CO2 Reaction with Hydrated Oil Well Cement under Geologic Carbon Sequestration Using Nanoclay Particles. J. Nat. Gas Sci. Eng. 2019, 68, 102902. [CrossRef]

29. Mahmoud, A.A.; Elkatatny, S.; Ahmed, S.A.; Mahmoud, M. Nanoclay Content Influence on Cement Strength for Oil Wells Subjected to Cyclic Steam Injection and High-Temperature Conditions. In Proceedings of the 2018 Abu Dhabi International Petroleum Exhibition \& Conference, Abu Dhabi, UAE, 12-15 November 2018. SPE-193059-MS. [CrossRef]

30. Peters, E.J. Porosity and Fluid Saturation. In Advanced Petrophysics; Live Oak Book Company: Austin, TX, USA, 2012; Volume 1, pp. 2-7. ISBN 978-1-936909-45-2.

31. Mahmoud, A.A.; Elkatatny, S. Effect of the Temperature on the Strength of Nanoclay-Based Cement under Geologic Carbon Sequestration. In Proceedings of the 2019 AADE National Technical Conference and Exhibition, Denver, CO, USA, 9-10 April 2019. AADE-19-NTCE-066.

32. Mahmoud, A.A.; Elkatatny, S.; Mahmoud, M. Improving Class G Cement Carbonation Resistance Using Nanoclay Particles for Geologic Carbon Sequestration Applications. In Proceedings of the 2018 Abu Dhabi International Petroleum Exhibition \& Conference, Abu Dhabi, UAE, 12-15 November 2018. SPE-192901-MS. [CrossRef]

33. Sanjuán, M.A.; Muñoz-Martialay, R. Influence of the age on the air permeability of concrete. J. Mater. Sci. 1995, 30, 5657-5662. [CrossRef]

34. Mohamed, A.K.; Elkatatny, S.A.; Mahmoud, M.A.; Shawabkeh, R.A.; Al-Majed, A.A. The Evaluation of Micronized Barite as a Weighting Material for Completing HPHT Wells. In Proceedings of the SPE Middle East Oil \& Gas Show and Conference, Manama, Bahrain, 6-9 March 2017. SPE-183768-MS. [CrossRef]

35. Alshubbar, G.D.; Coryell, T.N.; Atashnezhad, A.; Akhtarmanesh, S.; Hareland, G. The Effect of Barite Nanoparticles on the Friction Coefficient and Rheology of Water Based Mud. In Proceedings of the 51st U.S. Rock Mechanics/Geomechanics Symposium, San Francisco, CA, USA, 25-28 June 2017. ARMA-2017-0147. 
36. Elkatatny, S.M.; Nasr-El-Din, H.A.; Al-Bagoury, M. Evaluation of Ilmenite as Weighting Material in Water-Based Drilling Fluids for HPHT Applications. In Proceedings of the SPE Kuwait International Petroleum Conference and Exhibition, Kuwait City, Kuwait, 10-12 December 2012. SPE-163377-MS. [CrossRef]

37. Eilers, L.H.; Nelson, E.B. Effect of Silica Particle Size on Degradation of Silica Stabilized Portland Cement. In Proceedings of the SPE Oilfield and Geothermal Chemistry Symposium, Houston, TX, USA, 22-24 January 1979. SPE-7875-MS. [CrossRef]

(C) 2019 by the authors. Licensee MDPI, Basel, Switzerland. This article is an open access article distributed under the terms and conditions of the Creative Commons Attribution (CC BY) license (http://creativecommons.org/licenses/by/4.0/). 